Original Article

\title{
Low Incidence of Contrast Induced Nephropathy after Coronary Angiography in Patients with Advanced Chronic Kidney Disease Treated with Prophylactic Continuous Veno-venous Hemofiltration
}

\author{
Amal Abdel Ghani*, Naser Hussain, Bassam Al Helal \\ Department of Nephrology, Mubarak Al Kabeer Hospital, Ministry of Health, Kuwait
}

\begin{abstract}
Introduction: Contrast-induced nephropathy (CIN) is associated with increased risk of in-hospital morbidity and mortality. The purpose of this study was to find out whether continuous venovenous hemofiltration (CVVH) after coronary angiography in chronic kidney disease (CKD) patients is associated with a lower incidence of CIN than that reported in the literature.
\end{abstract}

Methods: All patients with CKD who underwent coronary angiography in the Chest Disease Hospital, Kuwait, between January 2004 and December 2005 were treated by CVVH after the procedure. Renal function was assessed before and after the procedure.

Results: A total of 98 patients were enrolled in the study, $52(53.1 \%)$ of whom were males. Their mean age was 60.7 years. Before the procedure, the mean serum creatinine level was $4.65 \mathrm{mg} / \mathrm{dl}$ and the mean creatinine clearance $(\mathrm{Cr} \mathrm{Cl})$ was $18.04 \mathrm{ml} / \mathrm{min}$. Patients underwent CVVH for a mean duration of 21.3 hours, after a mean time-interval of $44.3 \mathrm{~min}$. Their mean serum creatinine was $4.57 \mathrm{mg} /$ $\mathrm{dl}$ at discharge (within the first week after the procedure) and $4.78 \mathrm{mg} / \mathrm{dl}$ at 15 days after the procedure. Mean $\mathrm{Cr}$ $\mathrm{Cl}$ was $18.52 \mathrm{ml} / \mathrm{min}$ at discharge and $17.62 \mathrm{ml} / \mathrm{min}$ at 15 days after the procedure. There was no statistically significant difference between the mean serum creatinine and $\mathrm{Cr} \mathrm{Cl}$ values before and after the procedure. However, one patient $(1.02 \%)$ developed CIN and ended on regular hemodialysis. The in-hospital mortality was $0 \%$.

Conclusion: Patients with advanced CKD who undergo coronary angiography may be protected from further deterioration in their renal function after exposure to radiological contrast material if the procedure is immediately followed by CVVH. A randomized controlled clinical trial is needed to verify our encouraging results.

\footnotetext{
* Corresponding author; Mubarak Al Kabeer Hospital, Nephrology unit, PO Box 43787, code 3205 Hawally, Kuwait.

E mail: amalhassan90@hotmail.com
}

Keywords: contrast induced nephropathy, chronic kidney disease, continuous venovenous hemofiltration

\section{Introduction}

The incidence of contrast induced nephropathy (CIN) is now increasing, owing to the growing use of radiocontrast media (CM) in diagnostic as well as interventional procedures [1]. The most widely accepted definition of CIN is an increase of $25 \%$ or more, or an absolute increase of $0.5 \mathrm{mg} / \mathrm{dl}$ or more in serum creatinine from base line values at 24-72 hours following exposure to CM [2]. CIN is one of the leading causes of hospital acquired acute renal failure (ARF) and is associated with increased morbidity and mortality [3].

Among all procedures utilizing $\mathrm{CM}$ for diagnosis or therapeutic purposes, coronary angiography and percutaneous coronary intervention $(\mathrm{PCI})$ are associated with the highest incidence of CIN [1]. The overall incidence of CIN in the general population is reported to be $0.6-2.3 \%$ [4]. However, in several patient subsets the prevalence of CIN is significantly higher $[5,6]$. The incidence of CIN in patients with underlying chronic kidney disease (CKD) is extremely high, ranging from $14.8 \%$ to $55 \%$ [6-8]. The higher the base-line creatinine value, the greater is the risk of CIN [9]. Nevertheless, an increasing number of patients with $\mathrm{CKD}$ are being referred for PCI, owing to the greater prevalence of cardiovascular diseases among this group of patients [10]. CIN is a potentially reversible condition, however, currently available strategies, such as hydration and the use of $\mathrm{N}$-acetylcysteine, mannitol, furosemide, dopamine, fenoldopam, or other renoprotective drugs have been variably shown to be effective in patients with normal or mildly impaired renal function [11, 12]. Methods for prevention of CIN in patients with advanced renal failure remain unknown. Additionally, prophylactic hemodialysis, started immediately after the administration of CM to this group of patients didn't show any benefit in CIN prevention [13]. 
Abdel Ghani et al

Table 1: Baseline patients' morbidity characteristics $(\mathrm{n}=\mathbf{9 8})$

\begin{tabular}{lll}
\hline Pathology & Notes & Number (\%) \\
\hline Diabetes mellitus & & $79(80.6)$ \\
Hypertension & & $82(83.7)$ \\
Previous myocardial infarction & & $23(23.7)$ \\
Procedure & Diagnostic & $19(19.39)$ \\
& PCI* & $79(80.61)$ \\
Coronary artery disease & Normal vessels & $3(3.06)$ \\
& Single vessel & $5(5.1)$ \\
& Two vessels & $28(28.57)$ \\
& Three or more vessels & $62(63.26)$ \\
\hline
\end{tabular}

*PCI: percutaneous coronary intervention

Table 2: Baseline patients' important measurements that may affect renal outcome after cardiac catheterization (n=98)

\begin{tabular}{lll}
\hline & Mean $( \pm \mathrm{SD})$ & Range \\
\hline Age $($ years $)$ & $60.7 \pm 10.99$ & $36-81$ \\
Body mass index $\left(\mathrm{kg} / \mathrm{m}^{2}\right)$ & $28.39 \pm 4.71$ & $34-55$ \\
Baseline serum creatinine $(\mathrm{mg} / \mathrm{dl})$ & $4.65 \pm 0.9$ & $3.4-7.1$ \\
Baseline creatinine clearance $(\mathrm{ml} / \mathrm{min})$ & $18.04 \pm 4.26$ & $12.23-31.09$ \\
\hline
\end{tabular}

Continuous venovenous hemofiltration $(\mathrm{CVVH})$ is an alternative strategy to HD for prevention of CIN in high risk patients $[14,15]$.

The purpose of this study was to test the efficacy of prophylactic $\mathrm{CVVH}$ in the prevention of $\mathrm{CIN}$ in patients with advanced CKD.

\section{Methods}

A prospective single center study was conducted in Chest Disease Hospital of Kuwait from January 2004 to December 2006. All patients with CKD who were scheduled for PCI were included in the study. Inclusion criteria were age above 25 years, stable serum creatinine concentration above $3.39 \mathrm{mg} / \mathrm{dl}$ and creatinine clearance less than $35 \mathrm{ml} / \mathrm{min}$ within one month prior to the procedure. Exclusion criteria were presentation with cardiogenic shock, pregnancy, lactation, contraindications to heparinization, intravascular administration of contrast media or exposure to nephrotoxic drugs during the previous two weeks, use of non-steroidal anti-inflammatory drugs during the previous 48 hours, renal transplantation and, patients with end stage renal disease (ESRD) requiring regular dialysis. Angiotensin converting enzyme inhibitors were held on the day of the procedure. Acetylcysteine, mannitol and dopamine, were not used during the procedure. All patients gave a written informed consent.

Patients were started on CVVH as soon as possible after the procedure, and the time interval from contrast exposure to initiation of dialysis was recorded. CVVH was performed through a double lumen intravenous femoral catheter (Quinton, Bothell, WA) placed by the attending nephrologists before the procedure. CVVH for 18-24 hours was started using Prisma continuous fluid management system (Gambro Lakewood Co.) using M100 dialyzer sets (AN69 membrane), with surface area of $0.90 \mathrm{~m}^{2}$ and with bicarbonate buffered solution for continuous renal replacement therapy (CRRT) from Hospal with the following solute composition in $\mathrm{mmol} / \mathrm{l}$ : calcium 1.75, magnesium 0.5 , sodium 140, chloride 109.5, lactate 3 , bicarbonate 32 . Blood flow rate was set at 100 $\mathrm{ml} / \mathrm{min}$, and the substitution fluid rate was 2 liters/ hour without any additional fluid removal. Anticoagulation was achieved by giving heparin bolus of $500 \mathrm{IU}$ at the start of CVVH then constant heparin infusion to maintain activated partial thromboplastin time between 130-150 seconds. 
Blood urea nitrogen (BUN) and serum creatinine were measured before the procedure, at the end of the CVVH session, then daily for the following three days, at hospital discharge, and 15 days after the day of the procedure. Creatinine clearance $(\mathrm{Cr} \mathrm{Cl})$ was calculated at the same times using Cockcroft and Gault equation [16]. the incidence of contrast nephropathy, defined as more than $25 \%$ increase from baseline serum creatinine values within two weeks after the procedure was calculated. Emergency CRRT was performed if there was oliguria for more than 48 hours despite administration of more than 1 gram of furosemide over 24 hours, or if there was evidence of congestive heart failure, or if serum potassium was above $6 \mathrm{mmol} / \mathrm{l}$. CRRT was discontinued when there was evidence of recovery of renal function with the restoration of urine output of more than $500 \mathrm{ml} /$ day. The need for permanent hemodialysis was defined as persistent $\mathrm{Cr} \mathrm{Cl}$ less than $5 \mathrm{ml} / \mathrm{min}$. The incidence of CIN, in hospital mortality, and the need for long term dialysis was calculated.

Data were analyzed using SPSS for windows version 13 (SPSS, Inc, Chicago, IL). Continuous variables were expressed as mean $\pm \mathrm{SD}$, whereas categorical variables were expressed as frequencies and percentages.

\section{Results}

A total of 98 patients were enrolled in the study, 52 (53.1\%) of whom were males, and $46(46.9 \%)$ were females. Baseline patients' clinical and measurable indicators that may affect renal outcome after cardiac catheterization are summarized (Tables 1 and 2). Seventy nine patients $(80,6 \%)$ were diabetic and $82(83.7 \%)$ were hypertensive. Almost a quarter of them (23.7\%) had history of previous myocardial infarction and cardiac catheterization showed that 62 patients $(63 \%)$ had three vessel disease or more. Pre-procedure serum creatinine ranged from $3.42-7.14$ $\mathrm{mg} / \mathrm{dl}$ with a mean of $4.65 \pm 0.9 \mathrm{mg} / \mathrm{dl}$, pre-procedure $\mathrm{Cr} \mathrm{Cl}$ ranged from 12.23-31.09 $\mathrm{ml} / \mathrm{min}$, with a mean of $18.04 \pm 4.26 \mathrm{ml} / \mathrm{min}$.

All patients were subjected to post-procedure CVVH. The mean time interval between the procedure and the start of CVVH was $44.3 \pm 18.8 \mathrm{~min}$. The mean duration of the session was $21.3 \pm 2.1$ hours. None of the studied subjects had femoral catheter related complications, three patients $(3.06 \%)$ required catheter replacement for clotting. The CVVH course was smooth without intraprocedural complications. The mean serum creatinine after CVVH was $1.62 \pm 0.46 \mathrm{mg} / \mathrm{dl}, 3.51 \pm 0.52 \mathrm{mg} / \mathrm{dl}$ 48 hours after the procedure, $4.5 \pm 0.71 \mathrm{mg} / \mathrm{dl} 72$ hours after the procedure, $4.57 \pm 1.0 \mathrm{mg} / \mathrm{dl}$ at time of discharge, and $4.78 \pm 1.0 \mathrm{mg} / \mathrm{dl} 15$ days after the procedure (Figure 1). There were no statistically significant differences between any of the mean post-procedural serum creatinine values and the mean pre-procedural serum creatinine. Regarding $\mathrm{CrCl}$, its mean value was $18.52 \pm 4.61 \mathrm{ml} / \mathrm{min}$ at the time of discharge and $17.62 \pm 4.27 \mathrm{ml} / \mathrm{min}$ at 15 days after the procedure (Figure 2). One patient (1.02\%) developed CIN that required repeated CVVH sessions during hospitalization and ended up on regular long term hemodialysis. The in-hospital mortality was $0 \%$.

\section{Discussion}

Patients with CKD have a predisposition to accelerated atherosclerosis; they thus represent an increasing percentage of the patients undergoing PCI [17]. The clinical outcome of patients in whom CIN develops after PCI is particularly poor, with a reported in hospital mortality rate of more than 20 percent and cumulative one year mortality rate of more than 35 percent $[3,18-21]$. Mortality even increases to 45-62 percent if dialysis was required [19,21]. Given the clinical and prognostic implications, strategies to reduce the incidence of CIN are needed particularly in high risk patients [22]. Several strategies have been evaluated for the prevention of CIN. Among these strategies, only saline hydration [23, 24], the use of low-osmolality contrast agents [25] and treatment with $\mathrm{N}$-acetylcysteine [26-28] or fenoldopam $[29,30]$ have been shown to provide some protection and to reduce the incidence of CIN. However, the efficacy of these measures is still controversial in patients with severe renal impairment [27]. The pharmacokinetic properties of water soluble iodinated CM are such that they are distributed in the extracellular fluid only, are minimally protein bound, are not metabolized, and are excreted mainly by the glomerular filtration [31]. In normal subjects, elimination of $\mathrm{CM}$ takes place rapidly: after two hours approximately $50 \%$ of the CM is recovered in urine. In subjects with severe $\mathrm{CKD}$, the same $50 \%$ will be eliminated in urine 16-84 hours after injection of the CM [32]. Considering the properties of the iodinated $\mathrm{CM}$, it was hypothesized that it can be removed by dialysis. Our study showed that doing CVVH as soon as possible after contrast injection in patients with CKD reduced the incidence of CIN to $1.02 \%$ in this high risk group of patients. This percentage is significantly less than what has been reported in the literatures when other preventive strategies such as saline hydration or N-acetylcysteine were used in patients with CKD. Our results are in accordance with previous studies [33-36].

Hemodialysis (HD) and hemofiltration (HF) have both been studied for the prevention of CIN. To date, there have been few trials evaluating hemodialysis for prevention of CIN $[37,38]$. Hemodialysis and CVVH both effectively remove iodinated CM from the blood [39]. Despite this, a recent systemic review of studies 
Figure 1: Change in serum creatinine after the procedure

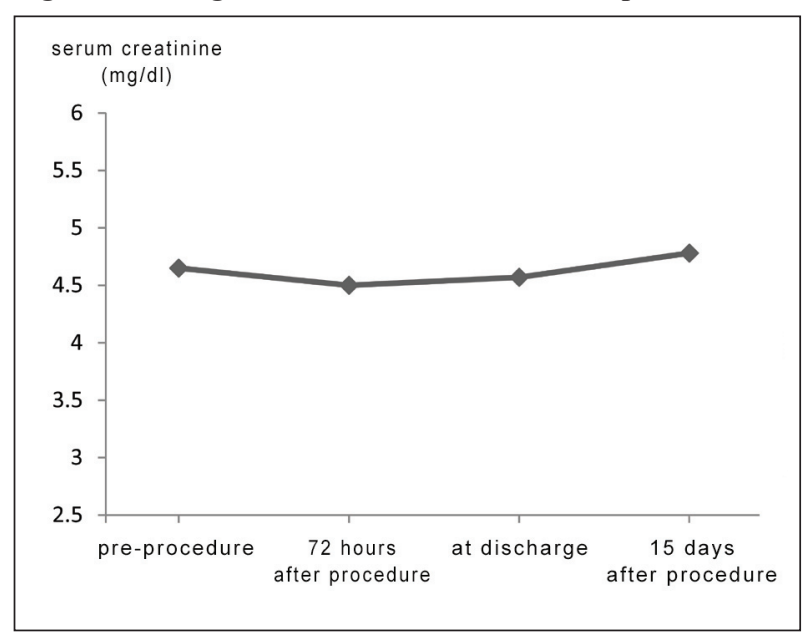

comparing the periprocedural HD with conventional prophylactic measures found that HD did not decrease the risk or the need for acute dialysis following CIN [36]. CVVHF and continuous venovenous hemodiafiltration (CVVHDF) have also been studied for the prevention of CIN after PCI in patients with CKD [36]. In 2003, Marenzi et al reported the superiority of CVVH over saline hydration in prevention of CIN after PCI in patients with $\mathrm{CKD}$, where CIN was reported in $5 \%$ of the CVVH group versus $50 \%$ in the control group [34]. Gabutti et al studied the effect of (CVVHDF) performed during and after PCI in patients with CKD and concluded that CVVHDF is not effective in prevention of CIN [40]. Marenzi et al compared the use of saline hydration with the use of pre- and post-procedure CVVH or the use of post-procedure CVVH and concluded that pre- and post-procedure CVVH was superior to the other two strategies [35]. On the other hand, Vogt et al didn't show any beneficial effect of prophylactic HD for 3 hours after the procedure [13]. Moreover, patients who received HD were more likely to have a decline in renal function and required additional HD treatment. A possible explanation for these results is that HD can induce hypovolemia and consequently may worsen renal ischemic injury, delay recovery of renal functions, and result in a need for prolonged dialysis [41]. On the other hand, CVVH is associated with hemodynamic stability, allows better hydration and regulation of volume status, allows infusion of large volume of bicarbonate containing solution, and allows removal of CM from the circulation with a resultant reduction in the kidneys' exposure to CM [14, 15, 42, 43]. In addition, heparin used during the procedure of CVVH may have a beneficial effect as it may inhibit acute inflammation, attenuate the ischemic reperfusion injury, and reduce the oxidative stress that may be involved in the pathogenesis of CIN [44, 45]. Lastly, considering
Figure 2: Change in creatinine clearance after the procedure

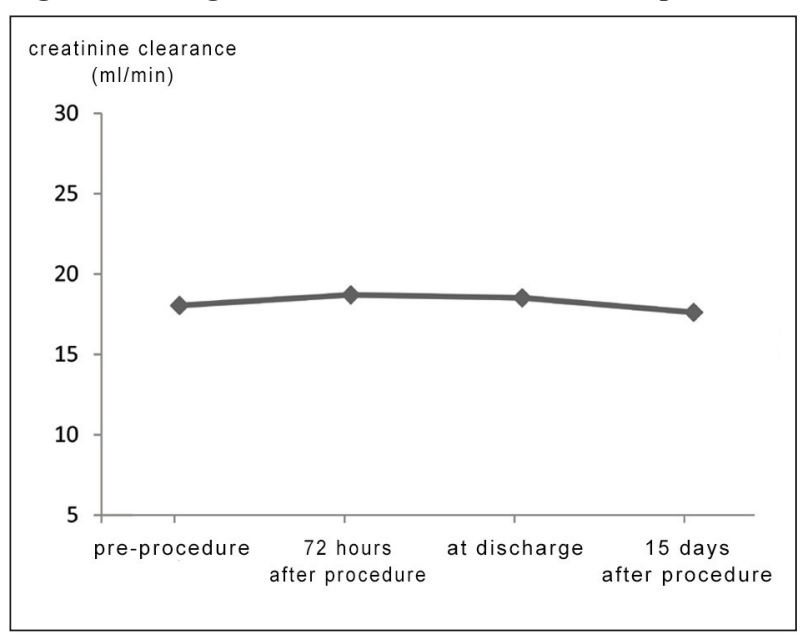

the relatively high cost and the time-consuming nature of CVVH, the limited availability of intensive care unit (ICU) beds and the lengthy immobilization of patients during CVVH, this procedure should be restricted to the high risk patients.

\section{Conclusion}

Despite CVVH being expensive, invasive, and time consuming, it may have a beneficial effect in preventing CIN after PCI in high risk patients with advanced CKD. CVVH should be considered as a preventive strategy for CIN after PCI in such patients. A randomized controlled clinical trial is needed to verify our encouraging results.

\section{Limitations of the study}

There was no control group, and the effect of CVVH was not compared with the conventional hydration protocols. This study was conducted in a single center and the results may not be generalizable to other centers. CVVH washes out creatinine, and may mask a transient rise in serum creatinin if such a rise was limited to the first 2-3 days after the procedure.

\section{References}

1. Nash K, Hafeez A, Hou S. Hospital acquired renal insufficiency. Am J Kidney Dis. 2002;39(5):930-6.

2. Mehran R, Nikolsky E. Contrast-induced nephropathy: definition, epidemiology, and patients at risk. Kidney Int. 2006;69(100):S11-5.

3. Levy EM, Viscoli CM, Horwitz RI. The effect of acute renal failure on mortality: a cohort analysis. JAMA. 1996;275(19):1489-94. 
4. Lasser EC, Lyon SG, Berry CC. Reports on contrast media reactions: analysis of data from reports to the US Food and Drug Administration. Radiology. 1997;203(3):605-10

5. Parfrey PS, Griffiths SM, Barrett BJ, Paul MD, Genge M, Withers J, Farid N, McManamon PJ. Contrast material-induced renal failure in patients with diabetes mellitus, renal insufficiency, or both. A prospective controlled study. N Engl J Med. 1989;320(3):143-9.

6. McCullough PA, Wolyn R, Rocher LL, Levin RN, O'Neill WW. Acute renal failure after coronary intervention: incidence, risk factors, and relationship to mortality. Am J Med. 1997;103(5):368-75.

7. Gruberg L, Mehran R, dangas G, Mintz GS, Waksman R, Kent KM, Pichard AD, Satler LF, Wu H, Leon MB. Acute renal failure requiring dialysis after percutaneous coronary interventions. Catheter Cardiovasc Interv. 2001;52(4):409-16.

8. Rihal CS, Textor SC, Grill DE, Berger PB, Ting HH, Best PJ, Singh M, Bell MR, Barsness GW, Mathew V, Garratt KN, Holmes DR Jr. Incidence and prognostic importance of acute renal failure after percutaneous coronary intervention. Circulation. 2002;105(19):225964.

9. Hall KA, Wong RW, Hunter GC, Camazine BM, Rappaport WA, Smyth SH, Bull DA, McIntyre KE, Bernhard VM, Misiorowski RL. Contrast induced nephrotoxicity: the effect of vasodilator therapy. J Surg Res. 1992:53(4):317-20.

10. Foley RN, Parfrey PS, Sarnak MJ. Clinical epidemiology of cardiovascular disease in chronic renal disease. Am J kidney Dis. 1998;32(5 Supppl 3):S112-9.

11. Gare M, Haviv YS, Ben-Yehuda A, Rubinger D, Bdolah-Abram T, Fuchs S, Gat O, Popovtzer MM, Gotsman MS, Mosseri M. The renal effect of low-dose dopamine in high risk patients undergoing coronary angiography. J Am Coll Cardiol. 1999;34(6):1682-8.

12. Abizaid AS, Clark CE, Mintz GS, Dosa S, Popma JJ, Pichard AD, Satler LF, Harvey M, Kent KM, Leon MB. Effects of dopamine and aminophylline on contrastinduced acute renal failure after coronary angioplasty in patients with preexisting renal insufficiency. Am J Cardiol. 1999;83(2):260-3, A5.

13. Vogt B, Ferrari P, Schönholzer C, Marti HP, Mohaupt M, Wiederkehr M, Cereghetti C, Serra A, Huynh-Do U, Uehlinger D, Frey FJ. Prophylactic hemodialysis after radiocontrast media in patients with renal insufficiency is potentially harmful. Am J Med. 2001;111(9):692-8.
14. Forni LG, Hilton PJ. Continuous hemofiltration in the treatment of acute renal failure. N Engl J Med. 1997;336(18):1303-9.

15. Marenzi G, Bartorelli AL, Lauri G, Assanelli E, Grazi M, Campodonico J, Marana I. Continuous veno-venous hemofiltration for the treatment of contrast-induced acute renal failure after coronary interventions. Catheter Cardiovasc Interv. 2003;58(1):59-64.

16. Cockcroft DW, Gault MH. Prediction of creatinine clearance from serum creatinine. Nephron. 1976;16(1):3141.

17. Jungers P, Massy ZA, Nguyen Khoa T, Fumeron C, Labrunie M, Lacour B, Descamps-Latscha B, Man NK. Incidence and risk factors of atherosclerotic cardiovascular accidents in predialysis chronic renal failure patients: a prospective study. Nephrol Dial Transplant. 1997;12(12):2597-602.

18. Murphy SW, Barrett BJ, Parfrey PS. Contrast nephropathy. J Am Soc Nephrol. 2000;11(1):177-82.

19. Gruberg L, Mintz GS, Mehran R, Gangas G, Lansky AJ, Kent KM, Pichard AD, Satler LF, Leon MB. The prognostic implications of further renal function deterioration within $48 \mathrm{~h}$ of interventional coronary procedures in patients with preexisting renal insufficiency. J Am Coll Cardiol. 2000;36(5):1542-8.

20. Rubenstein MH, Harrell LC, Sheynberg BV, Schunkert H, Bazari H, Palacios IF. Are patients with renal failure good candidates for percutaneous coronary revascularization in the new device era? Circulation. 2000;102(24):2966-72.

21. Best PJ, Lennon R, Ting HH, Bell MR, Rihal CS, Holmes DR, Berger PB. The impact of renal insufficiency on clinical outcomes in patients undergoing percutaneous coronary interventions. J Am Coll Cardiol. 2002;39(7):113-9.

22. Goel R, Berns JS. Can continuous venovenous hemofiltration prevent contrast induced nephropathy: is the dye already cast? Seminars in Dialysis. 2007;20(1):93-5.

23. Solomon R, Werner C, Mann D, D'Elia J, Silva P. Effect of saline, mannitol, and furosemide on acute changes in renal function induced by radiocontrast agents. N Engl J Med. 1994;331(21):1416-20.

24. Mueller C, Buerkle G, Buettner HJ, Petersen J, Perruchoud AP, Eriksson U, Marsch S, Roskamm H. Prevention of contrast media-associated nephropathy: randomized comparison of 2 hydration regimens in 1620 patients undergoing coronary angioplasty. Arch Intern Med. 2002;162(3):329-36. 
25. Rudnick MR, Goldfarb S, Wexler L, Ludbrook PA, Murphy MJ, Halpern EF, Hill JA, Winniford M, Cohen MB, VanFossen DB. Nephrotoxicity of ionic and nonionic contrast media in 1196 patients: a randomized trial. Kidney Int. 1995;47(1):254-61.

26. Tapel M, Van der Giet M, Schwarzfeld C, Laufer U, Liermann D, Zidek W. Prevention of radiographic contrast-agent-induced reductions in renal function by acetylcysteine. N Engl J Med. 2000;343(3):180-4.

27. Briguori C, Manganelli F, Scarpato P, Elia PP, Golia B, Riviezzo G, Lepore S, Librera M, Villari B, Colombo A, Ricciardelli B. Acetylcysteine and contrastagent associated nephrotoxicity. J Am Coll Cardiol. 2002;40(2):298-303.

28. Diaz-Sandoval LJ, Kosowsky BD, Losordo DW. Acetylcysteine to prevent angiography related renal tissue injury (the APART trial). Am J Cardiol. 2002;89(3):356-8.

29. Kini AS, Mitre CA, Kim M, Kamran M, Reich D, Sharma SK. A protocol for prevention of radiographic contrast nephropathy during percutaneous coronary intervention: effect of selective dopamine receptor agonist fenoldopam. Catheter Cardiovasc Interv. 2002;55(2):16973.

30. Madyoon H, Croushore L, Weaver D, Mathur V. Use of fenoldopam to prevent radiocontrast nephropathy in high-risk patients. Catheter Cardiovasc Interv. 2001;53(3):341-5.

31. Cattell WR, Fry IK, Spencer AG, Purkiss P. Excretion urography. Factors determining the excretion of Hypaque. Br J Radiol. 1967;40(476):561-71.

32. Lorusso V, Taroni $\mathrm{P}$, Alvino S, Spinazzi A. Pharmacokinetics and safety of iomeprol in healthy volunteers and in patients with renal impairment or end stage renal disease requiring hemodialysis. Invest Radiol. 2001;36(6):309-16.

33. Lee $\mathrm{P}, \mathrm{Ju}$ Chou K, Liu CP, Mar GY, Chen CL, Hsu CY, Fang HC, Chung HM. Renal protection for coronary angiography in advanced renal failure patients by prophylactic hemodialysis. J Am Coll Cardiol. 2007;50(11):1015-20.

34. Marenzi G, Marana I, Lauri G, Assanelli E, Grazi M, Campodonico J, Trabattoni D, Fabbiocchi F, Montorsi P, Bartorelli AL. The prevention of radiocontrast agent induced nephropathy by hemofiltration. N Engl J Med. 2003;349(14):1333-40.

35. Marenzi G, Lauri G, Campodonico J, Marana I, Assanelli E, De Metrio M, Grazi M, Veglia F, Fabbiocchi F, Montorsi P, Bartorelli AL. Comparison of two hemofiltration protocols for prevention of contrastinduced nephropathy in high-risk patients. Am J Med. 2006;119(2):155-62.

36. Cruz DN, Perazella MA, Bellomo R, Corradi V, de Cal M, Kuang D, Ocampo C, Nalesso F, Ronco C. Extracorporeal blood purification therapies for prevention of radiocontrast-induced nephropathy: a systemic review. Am J Kidney Dis. 2006;48(3):361-71.

37. Sterner G, Frennby B, Kurkus J, Nyman U. Does post-angiographic hemodialysis reduce the risk of contrast-medium nephropathy? Scand J Urol Nephrol. 2000;34(5):323-6.

38. Frank H, Werner D, Lorusso V, Klinghammer L, Daniel WG, Kunzendorf U, Ludwig J. Simultaneous hemodialysis during coronary angiography fails to prevent radiocontrast-induced nephropathy in chronic renal failure. Clin Nephrol. 2003;60(3):176-82.

39. Schindler R, Stahl C, Venz S, Ludat K, Krause W, Frei U. Removal of contrast media by different extracorporeal treatments. Nephrol Dial Transplant. 2001;16(7):1471-4.

40. Gabutti L, Marone C, Monti M, Malfanti M, Zwahlen U, Pasotti E, Colucci G, Schönholzer C. Does continuous venovenous hemodiafiltration concomitant with radiological procedures provide a significant and safe removal of the iodinated contrast ioversol? Blood Purif. 2003;21(2):152-7.

41. Murray P, Hall J. Renal replacement therapy for acute renal failure. Am J Respir Crit Care Med. 2000;162(3 Pt 1):777-81.

42. Merten GJ, Burgess WP, Gray LV, Holleman JH, Roush TS, Kowalchuk GJ, Bersin RM, Van Moore A, Simonton CA 3rd, Rittase RA, Norton HJ, Kennedy TP. Prevention of contrast-induced nephropathy with sodium bicarbonate: a randomized controlled trial. JAMA. 2004;291(19):2328-34.

43. Marenzi G, Lauri G, Grazi M, Assanelli E, Campodonico J, Agostoni P. Circulatory response to fluid overload removal by extracorporeal ultrafiltration in refractory congestive heart failure. J Am Coll Cardiol. 2001;38(4):963-8.

44. Derhaschnig U, Pernerstorfer T, Knechtelsdorfer M, Hollenstein U, Panzer S, Jilma B. Evaluation of antiinflammatory and antiadhesive effects of heparins in human endotoxemia. Crit Care Med. 2003;31(4):110812.

45. Sela S, Shurtz-Swirksi R, Shapiro G, Nasser L, Hamzi M, Shasha SM, Kristal B. Oxidative stress during hemodialysis: effect of heparin. Kidney Int Suppl. 2001;78:S159- 63. 